\title{
Psychological illness in medical outpatients
}

\author{
THOMAS R. TAYLOR \\ M.B.Ch.B., D.P.M., M.R.C.P.G., M.R.C.P.E. \\ Division of Medicine, \\ Victoria Infirmary, Glasgow
}

\begin{abstract}
Summary
A survey of psychological illness in medical outpatients reveals an incidence of $27.4 \%$ which is close to that of previous studies. The bulk of the cases are anxiety states and reactive depressions, and the great majority respond well to drugs and simple psychotherapy. The most important aetiological factors are shown to be disturbances of interpersonal relationships within the family with alcoholism, financial difficulties, illness and bereavement being of special importance. The problem of minor psychological illness is discussed from the viewpoint of community medicine, as well as that of the medical, surgical and gynaecological clinic. A simple scheme for the management of the more difficult cases, in co-operation with a Medical Social Work Department, is presented and is shown to work successfully during busy outpatient clinics.
\end{abstract}

\section{Introduction}

Most general physicians are familiar with the group of patients, often labelled 'functional', in whom no organic illness can be demonstrated. Such patients may complain of symptoms of anxiety or depression or only reveal these on close questioning. The size of the group is, to a great extent, a reflection of the problem of minor psychological illness in the community at large.

This study aims to indicate the incidence of this type of functional illness in a general medical outpatient clinic. Some attempt is made to investigate the aetiology, mode of presentation and response to treatment, and the place of the medical social worker in the management of such cases is discussed.

\section{The study}

The cases were seen in a general medical outpatients' clinic where the author was a full-time member of the medical staff. The study was conducted at the Victoria Infirmary outpatient clinic, Glasgow, and lasted 19 consecutive months, ending in December 1966. All new patients seen by the author in two medical clinics per week were included. The author shared a clinic with a consultant physician and patients were allocated alternately to each physician by the nursing staff without any knowledge of the presenting features or provisional diagnosis.

The total number of medical patients seen (see Table 1) was 336 . Of this total ninety-eight $(29.4 \%)$

TABLE 1. Diagnostic groupings

\begin{tabular}{lr}
\hline Total no. of medical patients seen & 336 \\
Total no. with psychological illnesses & 98 \\
Depressions & 43 \\
Anxiety states & 45 \\
Obsessional neuroses & 5 \\
Personality disorders & 2 \\
Simple schizophrenia & 1 \\
Presenile dementia & 1 \\
Mental deficiency & 1 \\
\hline
\end{tabular}

suffered from a psychological illness. The bulk of these ninety-eight patients suffered from either depression (forty-three) or anxiety states (forty-five) in almost equal numbers; obsessional neuroses (five) were next in frequency. In five of the forty-five anxiety states and nine of the forty-three depressions the psychological illness was secondary to an unrelated primary organic illness. Thus, one patient presented with clear-cut symptoms of chronic cholecystitis but was at least as concerned about symptoms of depression associated with domestic problems.

Cases where the psychological illness was clearly related to a primary organic illness were excluded. Thus, a patient with severe dyspepsia or incapacitating angina who had associated psychological symptoms would not be included in this series. This approach results in an underestimate of the incidence of psychological symptoms among the medical patients seen in this series since it would include only those patients in whom no primary organic illness was demonstrated by fairly thorough physical, biochemical, radiological and other investigations.

Among the depressions only three out of fortythree would be classified as endogenous. The large majority were reactive, i.e. with symptoms quite clearly referable to recent events in their life situation. Thirteen out of forty-five of the anxiety states 
TABLE 2. Age distribution

\begin{tabular}{lcccccccc}
\hline & Range & $1-20$ & $20-29$ & $30-39$ & $40-49$ & $50-59$ & $60-69$ & 70 and over \\
\hline Anxiety states & $12-82$ & 5 & 11 & 5 & 11 & 10 & 1 & 2 \\
Depressions & $12-78$ & 5 & 4 & 7 & 16 & 5 & 4 & 2 \\
Obsessional neurosis & $39-60$ & 0 & 0 & 1 & 2 & 0 & 2 & 0 \\
\hline
\end{tabular}

could be classified as acute, while the remainder were acute exacerbations of chronic anxiety states.

\section{General social data}

The general ratio of females to males was about $2 \cdot 1$ being $30 / 15$ in the anxiety states and $31 / 12$ in the depressions. The marital status was similar in each main group, $31 / 12 / 2: \mathrm{M} / \mathrm{S} / \mathrm{W}$ in the anxiety states and $29 / 12 / 2: \mathrm{M} / \mathrm{S} / \mathrm{W}$ in the depressions.

The age-range is shown in Table 2 with anxiety states fairly evenly distributed, while the depressions show a peak in the 40s. An interesting feature is the high proportion of teenagers (over $10 \%$ ).

\section{General practitioners' referral letter}

All the referral letters in the ninety-eight patients in the series were reviewed to determine the general practitioners' provisional diagnosis. In thirty-four out of ninety-eight cases (see Table 3) a psychological

TABLE 3. Diagnosis suggested in general practitioner's letter

\begin{tabular}{lr}
\hline Depressions & $17 / 43$ \\
Anxiety states & $13 / 45$ \\
Obsessional neuroses & $1 / 5$ \\
Personality disorders & $1 / 2$ \\
Simple schizophrenia & $0 / 1$ \\
Presenile dementia & $1 / 1$ \\
Mental deficiency & $1 / 1$ \\
Total & $34 / 98$ \\
\hline
\end{tabular}

illness was suggested and in the majority it concurred with the hospital diagnosis. It may well be that, in these thirty-four cases at least, the referral was aimed at the exclusion of physical disease or was a temporizing procedure on the part of an over-worked practitioner.

\section{Presenting symptoms}

The recognition of this group of patients may depend on the physician being familiar with the presenting symptoms which are commonly associated with such psychological conditions. Table 4 shows the presenting symptoms in the two major conditions. Gastro-intestinal symptoms are the commonest single category and could, presumably, just as easily result in referral to surgical as to medical outpatient clinics. Physicians are already familiar with the anxious patient who complains of left mammary pain or gastro-intestinal symptoms.
A complaint of 'loss of energy' or 'lethargy' (Table 4) often results in a provisional diagnosis by

TABle 4. Presenting symptoms

\begin{tabular}{lr}
\hline Anxiety states & \\
L. mammary pain & 9 \\
Headaches & 6 \\
Gastro-intestinal symptoms: & 16 \\
anorexia, nausea, abdominal pain, etc. & 6 \\
Palpitation, faintness & 8 \\
Others & \\
Depressions & 13 \\
No energy & 6 \\
Anorexia & 8 \\
Gastro-intestinal symptoms: & 4 \\
nausea, abdominal pain, dyspepsia & 3 \\
Headaches & 9 \\
L. mammary pain & \\
Others & \\
\hline
\end{tabular}

the general practitioners of anaemia or myxoedema. Hence it is always worthwhile looking for symptoms of depression in such cases.

\section{Aetiological factors}

In the course of this study the common precipitating factors were noted in each case and Table 5 shows a simple analysis of these. Domestic factors were prominent in over half of all cases. Included among these were marital disharmony, financial worries, alcoholism (in the patient or their spouse)

TABle 5. Common aetiological factors

\begin{tabular}{lr}
\hline Anxiety states & \\
Domestic factors & $27 / 45$ \\
Housewives' group & $3 / 45$ \\
Depressions & \\
Domestic factors & $21 / 43$ \\
Housewives' group & $3 / 43$ \\
\hline
\end{tabular}

and recurrent friction between parents and teenagers. Illness, especially if prolonged, as well as death in the immediate family were also important.

In the case of the teenagers, emotional problems, parental friction and job dissatisfaction were the most prominent factors.

Of particular interest among the females of both major categories were the housewives group (see Table 5). These patients exhibited symptoms of anxiety or depression; they found the drudgery and monotony of housework, especially with all the demands of a young family, overwhelming. 


\section{Treatment}

It is probably true to say that the treatment of this group of patients with psychological symptoms begins with the consultation itself. They may have had varying symptoms for several months and been unable to find a satisfactory explanation for them. If properly handled at the medical clinic, a great deal can be done by the simple routine of a careful history and a physical examination. There seems little doubt that the environment in the average medical outpatient clinic can contribute to reassuring the patient that his complaint is being taken seriously. To this extent the general physician has the advantage over the general practitioner who may not have the investigative services so readily at his disposal. A careful history, with special attention to such details as the patient's mood-state and any obvious precipitating factors, can usually quickly detect those among the normal run of medical outpatients who have a psychological illness. A thorough physical examination, including investigations such as full blood counts, X-rays and electrocardiogram all contribute to reassuring the patient. It often suffices to allow the patients to talk freely for a short timeabout their symptoms. This type of psychotherapy is probably the most valuable of all in these circumstances and is usually all that is possible to the average physician without a specialist's training in psychotherapy. Table 6 shows the forms of treatment used in the

TABLE 6. Treatment

\begin{tabular}{lcc}
\hline & Anxiety states & Depressions \\
\hline Psychotherapy alone & 18 & 15 \\
Psychotherapy + Medical Social & 8 & 10 \\
$\quad$ Worker & 10 & 2 \\
Psychotherapy + tranquillizer & 0 & 13 \\
Psychotherapy + anti-depressant & 3 & 0 \\
Tranquillizer & 2 & 0 \\
Child guidance & 2 & 0 \\
Psychotherapy+job & 2 & 3 \\
Nil & 45 & 43 \\
Total & & \\
\hline
\end{tabular}

two main diagnostic groups. No attempt was made in this series to probe very deeply into subconscious or other factors. The type of psychotherapy used was aimed at modifying current difficulties in the patient's life situation.

In other cases such psychotherapy was combined with a drug; a tranquillizer in the anxiety states and an anti-depressant in the depressions. Since most of the depressions were reactive in type, psychotherapy was usually necessary.

In three of the chronic long-standing anxiety states it was obvious that the value of such psychotherapy would be very limited and so a tranquillizer alone was used.
In two cases a child was referred to a child guidance clinic. In one case the child had been referred because of headaches but a careful history revealed a clear-cut behaviour disorder; in the other case the mother was referred with possible anaemia but, instead, had a mild reactive depression which was clearly due to her child's behaviour disorder.

Job dissatisfaction was a major factor in two cases, both teenagers, and symptoms responded well to redeployment.

It is essential that any scheme of treatment for this group of patients who are seen, after all, in a medical clinic, should fit easily into the time available to the busy physician. Any scheme which does not accept these limitations is bound to break down eventually. The main problem would seem to be the psychotherapy. If the variety of psychotherapy described above is used, the total time necessary at the first visit need only be $20 \mathrm{~min}$. This is especially true if the patient is allowed to continue talking during part of the physical examination. In the more demanding cases, the medical social worker, with her specialized training, can be used to give the extra time and effort needed.

\section{Response to treatment}

The majority of patients were symptom-free after three months (Table 7) and less than $10 \%$ of those who continued to attend failed to improve. The father of one child with an anxiety state, dismissed the psychological explanation of the child's symptoms and refused treatment.

Over $20 \%$ could be discharged after the first visit. In many of these simple psychotherapy had reassured them that their symptoms would settle quickly. In other cases the delay in waiting for an outpatient appointment meant that they were already improving before the consultation.

TABle 7. Progress

\begin{tabular}{lrr}
\hline & Anxiety states & Depressions \\
\hline Discharge after first visit & 14 & 5 \\
Failure to keep second appointment & 5 & 11 \\
Slight improved after 3 months & 2 & 2 \\
Much better after 3 months & 19 & 21 \\
Refused treatment & 0 & 1 \\
No improvement & 5 & 3 \\
Total & 45 & 43 \\
\hline
\end{tabular}

Of those who failed to attend for a second appointment, some were improving and satisfied with the explanation of their symptoms. Others, especially the chronic anxiety states, presumably felt that no benefit would come from further visits.

It is, on the whole, reassuring that the majority improved within 3 months. 
In a few cases, all chronic anxiety states, further analysis of the records showed they had reappeared within six months at other clinics (e.g. dermatological or surgical) with further symptoms probably related to the same underlying psychological illness.

It seems essential that as many as possible of the cases should be dealt with effectively within one to two visits to relieve the burden on the patient and the expense to the Health Service.

\section{The role of the medical social worker}

A number of the patients in this study had problems too complicated to be adequately documented or dealt with during a busy clinic. An arrangement was made with the medical social worker attached to the appropriate medical inpatient unit to cope with such cases.

It usually became clear within the first 5-6 min of the consultation that a case was too complex to be quickly resolved. In these cases the examination and investigations were rapidly completed and the psychological basis of the symptoms was explained in general terms. It was then suggested to the patient that they discuss them with the medical social worker who is professionally qualified to deal with such problems. After contacting the medical social worker (M.S.W.) by 'phone and giving general details of the case, the clinic could be continued while the patient waited for an interview. In some cases the M.S.W. could manage an interview immediately, while in others a later date in the social service department or a home visit was arranged. No disruption of the clinic was necessary and the special skills and training of the M.S.W. were used in a similar way to those of the physiotherapist, speech therapist or dietitian. Periodic verbal reports of the patient's progress were made and a brief summary of relevant aetiological factors and response to therapy was inserted later to complete the case record.

The type of cases dealt with by the M.S.W. varied but in general there was a predominance of housewives with depressive symptoms and teenagers with emotional problems, both of whom clearly indicated the benefit of discussing their problems with a sympathetic listener. The response to treatment in most cases was excellent.

This arrangement was warmly welcomed by the social work department for two main reasons:

(a) It provided a rich supply of varied case studies for their students. Cases were assigned to them and were followed up in detail with home visits under the supervision of a M.S.W.

(b) In general the cases were more interesting and more satisfying, from the prognostic point of view, than the usual inpatient referrals for convalescence, $h=$ me help or financial assistance.

From the patient's point of view the treatment is, on the whole, better than that available from most physicians who have neither the training nor the time to manage such cases.

In this series, eighteen cases out of the ninety-eight were referred to the social service department. The referral rate would be much higher if the physician had less psychiatric training. From calculations based on a referral rate of twice that of this series (i.e. thirty-six out of ninety-eight psychological cases, or thirty-six out of all 336 medical cases) one extra M.S.W. would be necessary to cope with an outpatient load of new cases of 9600 a year (i.e. the total number of new cases in medicine, surgery and gynaecology treated as outpatients in this hospital) where surgical and gynaecological clinics were handling psychological problems in an identical manner. Presumably the outpatient work would be shared out among the group of social workers in their department.

\section{Discussion}

The general problem of minor psychological illness in the community has been studied from the viewpoint of general practice, of hospital inpatients and as it manifests itself in outpatient clinics. The studies in general practice produce incidences varying from 4 to $12 \%$. Logan \& Cushion (1958) in a survey involving over 100 general practices found a prevalence rate for neurosis among adults of $4.6 \%$ while Kessell (1960) in a similar survey found the 1 year prevalence of the same condition was $8 \%$. Fry $(1960)$ noted that $12 \%$ of his patients had consulted him with a psychoneurotic illness and more recently Kellner (1965) found, in a working-class practice, that $9 \%$ of patients suffered from minor psychological illnesses. Finally, Shepard et al. (1964) in a survey of a large number of general practices in London, established that a general practitioner would be consulted for a neurotic illness by $8.9 \%$ of adults registered with him in any one year.

The reflection of this problem in medical inpatients is familiar to the hospital physician in its extreme form as attempted suicide and less dramatically as minor complaints of anxiety, depression or somatic symptoms in his ward patients. Studies of this inpatient aspect of the general problem are less frequent but Eilen Berg (1965) has studied inpatient referrals to the Psychiatric Department from the general wards of the Mayo Clinic, noted an incidence of $2 \%$ and has reviewed other similar studies. Crisp (1968) in a recent review has surveyed the problem from the view point of both the inpatient and outpatient population. He discussed in some detail a large personal series of inpatient referrals to an academic psychiatric unit in a general hospital.

The high incidence $(29.4 \%)$ of psychological illness in medical outpatients demonstrated in this study is 
already accepted and acknowledged by many physicians. It must be seen as a manifestation of the same problem in the community at large (Shepard et al., 1964), discussed earlier. The higher incidence in the outpatient population highlights one route of disposal of such cases by the general practitioner. The patient in the community at large may find himself in an intolerable position because of the stress of financial, marital or other worries, and reacts to this stress in a number of ways. Some may come to the general practitioner with complaints of depression, anxiety or insomnia; others may develop psychosomatic symptoms such as asthma, peptic ulcer or skin disorders. The former group may be referred to a psychiatric clinic or treated by the general practitioner. The psychosomatic type are usually treated symptomatically. Yet another group has been delineated by this study and in other similar studies in surgical and gynaecological clinics. These patients consult their general practitioner with physical symptoms which mask their underlying psychological problems. Balint (1957) has discussed the choice of symptoms by such patients. He has shown that they will often present their illness in a 'medical' and not a 'psychiatric' context. Thus a patient complaining of depression or lack of interest is less likely to gain sympathy or be allowed to talk about himself, than if he complains of lack of energy or dyspepsia. The general practitioner or hospital physician is more confident of dealing with the patient as a whole if the presenting symptom is apparently organic. These latter presenting symptoms, says Balint (1957) are discarded if the real reason for the consultation, the underlying emotional problem, is brought to light. Certainly, in this study these original organic token symptoms are usually forgotten if the less obvious psychological symptoms and stresses are discussed. This view of presenting symptoms as 'token' symptoms suggests that the choice often results in the patient being referred to any one of several specialities. Thus dyspeptic symptoms might mean referral to a surgical or medical outpatient clinic, low-back pain to a gynaecological or orthopaedic clinic, and frequency to urological or gynaecological departments. The review of the general practitioners' referral letters (Table 3) shows that in at least a third of cases the consultation was intended to exclude physical disease rather than an attempt to treat the underlying emotional problem. Davies (1964) in a similar review found only sixteen out of thirty-eight referral letters mentioned that the patient was anxious or under stress.

Several studies have concentrated on the medical outpatient population (Roberts \& Morton, 1952; Culpan, Davies \& Oppenheimer, 1960; Sainsbury, 1960; Mannucci, Friedman \& Kaufman, 1961;
Stoeckle, Zola \& Davidson, 1962; Davies, 1964; Maclay, 1965) while others have demonstrated a similar problem in surgical outpatients (Zwerling et al., 1955; Culpan et al., 1960), in gynaecological clinics (Bryson, 1945; Morris \& O'Neill, 1958; Culpan et al., 1960), and in a casualty department (Mestitz, 1957) while Priest (1962) covered this particular problem in the course of a large (1000 cases) survey of outpatients in general.

The incidence found in this study $(29.4 \%)$, is very close to the average $(27.3 \%)$ in eleven different surveys of medical outpatients reviewed by Davies (1964). Brodman et al. (1952), found a similar incidence of $30 \%$ while Maclay (1965) found that $26 \%$ of a personal series of medical outpatients suffered from a psychological illness. In all of these studies the figures quoted refer to purely psychological cases and exclude combination of organic and psychological diagnoses in the same patient. Stoeckle et al. (1962) in an extensive review of the subject, emphasized the wide variation in terminology in such studies, and its effect on estimates of incidence which varied from 5 to $70 \%$ in the papers he reviewed.

In surgical clinics, Bryson (1945) found a comparable incidence of about $7 \%$, while Culpan et al. (1960) found $5 \%$. In gynaecological clinics Culpan et al. (1960) found over $50 \%$ of patients had emotional problems, although they did not confine themselves to non-organic cases. The large discrepancy between surgical and medical clinics is interesting and the reason is not immediately obvious.

The sex incidence of twice as many females is identical in both anxiety states and depression and is similar to that found by Kellner (1965) for neurosis in general practice, and Culpan et al. (1960) in medical outpatients. The anxiety states showed a fairly even age distribution (Table 2), but the depressions gave a peak in the 40 s with a large preponderance of the reactive type. The menopause combined with the domestic problems referred to may explain this peak. The relatively high incidence in this study of teenagers whose emotional problems have presented as physical illness, probably reflects the perennial problem of comm unication with parents and other adults. Certainly they responded well to simple support and a sympathetic hearing from the Medical Social Worker.

The aetiological factors (Table 4) are predominantly domestic. A small number of patients, however, exhibited a reaction to over-activity. Several successful executives presented with dyspeptic symptoms which masked an acute anxiety state. This was related to a spiral of increasing success and of expanding opportunity and responsibility. Their response to general advice and psychotherapy was poor and after 3 months they continued to overwork. 
Most of the domestic factors could be summarized as disturbances of interpersonal relations in the family, although, like the series of Pemberton (1951) and of Davies (1964), death or severe illness of the spouse or near relative were frequently important.

Of special interest among the aetiological groupings were the housewives group. These women, all in the 20-40 age range, presented with complaints of lack of energy (provisional diagnosis anaemia), anorexia or weight loss (provisional diagnosis peptic ulcer), or weight loss (provisional diagnosis 'thyrotoxicosis' or 'malabsorption syndrome'). They were all married women with a young family or with older children recently gone to school or left home. In the former group the patient felt trapped by the continuous demands of a young family, with no opportunity to earn an independent income, however small. The daily round of housework and the company of young children and other housewives left them bereft of intellectual stimulus or independence. The situation was often made worse by a recent, often unplanned, pregnancy which postponed for several years a return even to part-time work. In intelligent women the conflict between their need for intellectual stimulus and personal independence, and their responsibility for young children, produced anxiety or depression masked by 'token symptoms'. The other similar group of 'house-bound housewives' were those whose children had left home or gone to school, and who were bored with inactivity. Both types responded well to psychotherapy, to the appropriate drugs and to support from the medical social worker. Part-time work and nursery facilities for young children (2-3 half-days per week) usually resulted in a more stable life situation.

The problems of treatment have been discussed earlier. The uses of tranquillizers and anti-depressants were conventional: hence the main problem lay with the psychotherapy. For the average physician this would present difficulties of lack of time and expertise. A great deal can be done by sympathetic listening, and the scheme described above, using the Medical Social Work Department, should cover adequately most cases where more prolonged or intensive support is needed. Certainly with this scheme, colleagues have been able to cope with all those patients in whom they suspect a psychological problem. The medical social worker is able to provide a rapid screening interview in the Outpatient Department in cases where there is doubt. From our own experience this scheme works smoothly and satisfactorily in a busy clinic. Recently surgical colleagues have had similar success.

Davies (1964) has shown that 19/51 cases in his series needed simple psychological support, while $18 / 51$ needed more complex psychiatric treatment than the average general practitioner or hospital physician could, because of deficiencies in his training, provide. From this series there is little doubt that both these groups could be managed satisfactorily by the Medical Social Worker, leaving only the occasional very difficult cases to be referred to a psychiatric clinic. If their underlying psychological problem is not tackled, another token symptom may appear. Thus, Macy \& Allen (1933) showed that of 235 patients diagnosed at the Mayo Clinic as having a neurotic illness, 200 had had 280 separate operations, including gynaecological ones, during a 6-year follow-up period. Even within the 18-month period of this study several patients, all with chronic anxiety states, had appeared at surgical and dermatological clinics. Perhaps if less attention had been paid to their emotional problems many others in this series would have behaved likewise. It would seem to make good sense, both from the patients' and from the hospital's point of view, that as many as possible of the underlying problems should be dealt with promptly and effectively. The approach described in this paper makes this possible in a busy clinic where physicians have no specialized psychiatric background.

\section{Acknowledgments}

I would like to acknowledge the help given to me byo Dr A. A. F. Peel of the Medical Division, Victoria Infirmary for his permission to use cases in his unit. To Dr Thomas Semple, Chairman of the Medical Division, Victoria Infirmary, for his advice and comments and in particular, to Dr J. B. McGuinness for his help in preparing this study and for reading and commenting on the original manuscript as well as for his help in allowing access to patients in his medical clinic.

I am also endebted to the the Secretarial Staff in this Unit for the assistance they have given me in preparing this manuscript.

Finally, I would like to express my sincere thanks to Miss Maureen Willis and her colleagues in the Social Service Department of the Victoria Infirmary, Glasgow, for their generous help and enthusiastic co-operation in this study.

\section{References}

Balint, M. (1957) The Doctor, His Patient and the Illness. Pitman Medical, London.

Brodman, K., Erdmann, A.J., Longe, J., Gershenson, C.P \& WolfF, H.G. (1952) The recognition of emotional disturbances in a general hospital. J. clin. Psychol. 8, 289.

BRYSON, E. (1945) The psychosomatic approach in gynaecological practice. Practitioner, 155, 378.

CRISP, A.H. (1968) The role of the psychiatrist in the general hospital. Postgrad. med. J. 44, 267.

Culpan, R., Davies, B. \& OpPenheimer, A.W. (1960) Psychiatric illness at a medical and a surgical outpatient clinic. Comprehens. Psychiat. 1, 228.

DAvies, B. (1964) Psychiatric illness at general hospital clinics. Postgrad. med. J. 40, 15.

EILENBERG, M.D. (1965) Survey of inpatient referrals to an American psychiatric department. Brit. J. Psychiat. 111, 1211.

FRY, J. (1960) What happens to our neurotic patients. Practitioner, 185, 85. 
Kellner, R. (1965) Neurosis in general practice. Brit. J. clin. Pract. 19, 681.

Kessele, W.I.N. (1960) Psychiatric morbidity in a London general practice. Brit. J. prev. Soc. Med. 14, 16.

Logan, W.P.D. \& Cushion, A.A. (1958) Studies on Medical Population Studies, Vol. 1, p. 14. H.M.S.O., London.

MACLAY, L. (1965) The 'functional' medical outpatient. Brit. J. Psychiat. 111, 34.

Macy, T.W. \& Allen, E.V. (1933) A justification of the diagnosis of chronic nervous exhaustion. Ann. intern. Med. 7, 861 .

Mannucci, M., Friedman, S.M. \& Kaufman, M.R. (1961) Survey of patients who have been attending non-psychiatric outpatient department services for 10 years or longer. J. Mt Sinai Hosp. 28, 32.

Mestitz, P. (1957) A series of 1817 patients seen in a casualty department. Brit. med. J. 2, 1108.

MorRIS, N. \& O'NeILl, D. (1958) Outpatient gynaecology. Brit. med. J. 1, 1038.
Pemberton, J. (1951) A sociomedical study of 200 hospital medical patients. Lancet, i, 224.

Priest, W.M. (1962) A thousand outpatients. Lancet, ii, 1043.

ROBERTS, B.H. \& MORTON, N.M. (1952) The prevalence of psychiatric illness in a medical outpatient clinic. New Engl. J. Med. 246, 82.

SaInsbury, P. (1960) Psychosomatic disorders and neurosis in outpatients attending a general hospital. J. psychosom. Res. 4, 261.

Shepard, M., Cooper, B., Brown, A.C. \& Kalton, G.W. (1964) Minor mental illness in London. Brit. med. J. 2, 1359.

Stoeckle, J.D., ZolA, I.K. \& Davidson, G.E. (1962) The quantity and significance of psychological distress in medical patients. J. chron. Dis. 17, 959.

ZWerling, L., Titchener, J., GotTSCHALK, L., LeVine, M., Culbertson, W., Cohens, S. \& Silver, H. (1955) Personality disorder and the relationships of emotion to surgical illness in surgical patients. Amer. J. Psychiat. 112, 270. 